\title{
Impact of Test Anxiety on Test Scores of Pre-service Teachers in Northern Cyprus
}

\author{
Chinaza Solomon Ironsi \\ Department of English Language Teaching, Near East University, Near East Boulevard, PK: \\ 99138, North Cyprus, Mersin 10 Turkey
}

\begin{abstract}
A lot has been written with regards to the subject of anxiety and its role on influencing learning outcomes yet it seems the issue of anxiety is continuously debated by research and academic scholars. While teachers may think that issues of anxiety in education are either overhyped or overemphasized, learners think otherwise. To analyze the views of the preservice teacher on the concept of test anxiety especially on its influence on the academic performance of students, a mixed research design was adopted for this study. An experimental approach followed by semi-structured interviews were used to elicit information on the impact of test anxiety on the academic performance. A total of 42 participants were purposively chosen which were divided into 2 groups, A (control group) and B (experimental group). A reliable and validated post-test was administered where there was an induced stress on the experimental group before commencing an examination. The findings of this study argued that though test anxiety affected students test scores to a large extent, other possible factors were responsible for learner's test scores as well. The study suggests the need for rethinking ways through which examinations are organized to reduce incidence of test anxiety among test takers. The major limitation of the study was the small sample size. Thus, the use of a larger sample for future researches must be considered.
\end{abstract}

Keywords: anxiety, test anxiety, academic performance, measurement and evaluation, test scores, North Cyprus

Suggested Citation: Ironsi, C. S. (2020). Impact of Test Anxiety on Test Scores of Preservice Teachers in Northern Cyprus. International Journal of Educational Management and Development Studies, Volume 1, Issue 2, pp. 19 - 36. 


\section{Introduction}

A lot has been written and researched with regards to anxiety in education yet it seems that this topic continues to resurface again. Research on test anxiety seems to have a long tradition as many scholars posit that this issue has both psychological and academic impacts on the learners. For decades, one of the most popular ideas in anxiety-related literature, as it bothers on education, hinges that learners experience anxiety while learning especially during evaluation situations (Krispenz, Gort, Schültke \& Dickhäuser, 2019; Safeer \& Shah, 2019), Recent theoretical developments have revealed that educational institutions have tried to introduce strategies that will assist curb the continuous cases of anxiety during examination situations (Ringeisen \& Heckel, 2019; Harris, Grunspan, Pelch, Fernandes, Ramirez \& Freeman, 2019), though it seems a lot has not been achieved.

Literature has emerged which addresses the opinions of all stakeholders on the role of anxiety especially in educational assessments. Most of them affirm that anxiety affects the learner's performance and may influence negative learning outcomes (Owan, Eno \& Esuong, 2019; Amini, Amini \& Reamen, 2019; Wallis, Gretz, Rings \& Eberle, 2019). Previous and recent literatures focus on explaining the concept of test anxiety and its influence on educational outcomes (Trigueros, Padilla, Aguilar-Parra, Rocamora, Morales-Gázquez \& López-Liria, 2020; Woldeab \& Brothen, 2019; Riyazi, 2019). However, only limited few critically experiment with the issue at hand, especially where learners are the core participants of the study. This seems to be a common problem in examining the role of test anxiety in education. It is believed that the inability of studies to carry out researches that experiment on the influence of test anxiety on academic performance of students leads to myriad problems in the pedagogy of education. One of the issues is that most studies are too general in the context of test anxiety. In addition, the researchers' approach to the concept of test anxiety differ as they assume that the anxiety will continue to linger due to the individual differences of the learners.

Other studies have failed to address test anxiety from a pedagogical point of view. Most of them have adopted a general approach. One way to overcome this problem is to extensively carry out experiment-based research that would unveil possible impacts of test anxiety on the academic performance. This probable solution to the problem is proposed in 
INTERNATIONAL JOURNAL OF EDUCATIONAL MANAGEMENT AND

DEVELOPMENT STUDIES

Volume 1, Issue 2 • December 2020 • ISSN 2719-0633 (PRINT) 2719-0641 (ONLINE)

this study. The researcher believes that it will be of great interest to know whether issues of test anxiety really exist or the concept is just overhyped by researchers. Thus, the impact of test anxiety on academic performance was analyzed and investigated through an experimental approach. In addition, the perception of the preservice teachers with regards to test anxiety were taken during the evaluation periods.

\section{Literature review}

There are a lot of literature which primarily prove that issues of test anxiety exist in most of the educational institutions and in a way have a psychological impact on learners (Poorman, Mastorovich \& Gerwick, 2019; Yusefzadeh, Iranagh \& Nabilou, 2019). In addition, previous researches also discussed that learners experienced several symptoms during evaluation period which manifest anxiety effects. Seminal contributions have been written by lots of authors on the issue and posit that though anxiety exists during learning but there are limited practical efforts made to reduce its impact on learning outcomes (Zeidner, 2010; Carsley, Heath \& Fajnerova, 2015). There are series of studies indicating a need to pay more attention to anxiety among learners as it may affect the quality of instruction and create problems during assessment and evaluation (Yusefzadeh, Iranagh \& Nabilou, 2019; Gerwing, Rash, Allen Gerwing, Bramble \& Landine, 2015; von der Embse, Jester, Roy \& Post, 2018). However, there are also numerous studies which suggested that anxiety may be required to ensure that learners take teaching and learning seriously (Brady, Hard \& Gross, 2018; Amy, 2017; Dan \& Raz, 2015; Abdollahi \& Abu Talib, 2015). Yet, some authors suggest that anxiety among students ought not to be a determinant of seriousness in academic activities though students can maximize it for their own good (Brady, Hard \& Gross, 2018; Amy, 2017; Alicia, 2018). Relatively, there is a need to reduce affective filter to the barest minimum while teaching students (Ironsi, 2017) even during evaluation periods. The affective filter must be reduced during lessons as some students may feel uneasy while lessons are ongoing especially where everyone is expected to contribute to classroom discussions (Ironsi, 2017; Gerwing, Rash, Allen Gerwing, Bramble \& Landine, 2015). Prior studies also affirmed that a conducive learning environment is essential to bringing out the best in a student during lessons especially while students are expected to contribute meaningfully during lessons (Dan \& Raz, 2015; Krispenz, Gort, Schültke \& Dickhäuser, 2019). As the issue of anxiety is 
INTERNATIONAL JOURNAL OF EDUCATIONAL MANAGEMENT AND

DEVELOPMENT STUDIES

Volume 1, Issue 2 • December 2020 • ISSN 2719-0633 (PRINT) 2719-0641 (ONLINE)

prevalent to students, researchers assume that the possibilities of anxiety during lessons and examination period extremely call for a revisit on the approaches adopted for the evaluation of learners (Safeer \& Shah, 2019; Ringeisen \& Heckel, 2019).

Numerous studies proved that test anxiety affect the performance of the students. A condition of uneasiness that induces fear may not allow test takers to excel during examination (Amini, Amini \& Reamen, 2019; Poorman, Mastorovich \& Gerwick, 2019; Zeidner, 2010). For instance, there are cases where a test taker may be conversant with knowledge explained in the classroom but may not be able to perform excellently during examinations. As it was recognized that individual differences of learners may influence and induce anxiety, it also calls for adequate measures in place to ensure that anxiety-free examinations are conducted (Abdollahi \& Abu Talib, 2015; Sarı, Bilek \& Çelik, 2018). It was observed that students naturally feel anxious during examinations which in no case justify that they did not understood information or gained knowledge during lessons (Weems, Scott, Graham, Banks, Russell, Taylor \& Marino, 2015).

There are still several questions on test anxiety which remained unaddressed. On a particular note, most of the literature mainly focus on the teachers' experience and have not taken into account the perception of learners on the issue. While a teacher may believe that the issue of test anxiety could be unnecessary, literature and reports indicated that learners think that more conventional approaches to the evaluation should be adopted (Stoeber, Haskew \& Scott, 2015; Caspersen, Smeby \& Olaf Aamodt, 2017). It is argued that examinations are not a true test of knowledge especially with the way some evaluation and assessments are being conducted in schools (Vatterott, 2015; Townsley \& Buckmiller, 2016; Westerberg, 2016). Most studies suggest that though anxiety could have an impact on a student, it may necessarily not be the sole reason for poor learning outcomes of learners (Brady, Hard \& Gross, 2018; Amy, 2017; Alicia, 2018).

The previous studies on test anxiety may not be considered conclusive as they lack experimental approach to the critical analysis of the impact of test anxiety on the academic performance of learners. As in the case of the previous cited herein, they mostly focused exclusively on test anxiety in general or any other academic concerns. Although other cited studies illuminated that test anxiety affects learners, there are still very limited studies that 
INTERNATIONAL JOURNAL OF EDUCATIONAL MANAGEMENT AND

DEVELOPMENT STUDIES

Volume 1, Issue 2 - December 2020 • ISSN 2719-0633 (PRINT) 2719-0641 (ONLINE)

examined its impact on academic performance by eliciting information directly from preservice teachers. Despite decades of research, the issue of test anxiety continues to be debated among scholars. While some believe it is a serious issue in education, others posit that it is overhyped by research (Brady, Hard \& Gross, 2018; Alicia, 2018). Although there were numerous studies conducted, further studies are necessary to address other critical aspects of test anxiety.

\subsection{Theoretical framework}

Test anxiety continues to pose a threat to the achievement of the learning outcomes as posited by numerous researchers (Amini, Amini \& Reamen, 2019; Poorman, Mastorovich \& Gerwick, 2019; Yusefzadeh, Iranagh \& Nabilou, 2019; Gerwing, Rash, Allen Gerwing, Bramble \& Landine, 2015). Relatively, the Yerkes Dodson law suggests that a clear relationship exists between pressure and performance indicating that when pressure is usually applied to an individual there is a possibility that it could influence performance (Corbett, 2015). This study hinges on the assumption that the application of pressure in the form of stress or uneasiness could play a significant role in influencing the academic achievement levels of preservice teachers. Though this study upholds that pressure could have a positive impact on performance; when it is applied excessively it could result to a negative impact. It is relevant to note that in academia, it is yet to be measured what could be the adequate pressure, uneasiness, or anxiety needed for positive learning outcome though the law suggests that when pressure is too high, performance tends to reduce (Corbett, 2015). This study believes that the application of pressure in any form during academic activities could influence the academic performance and achievements of preservice teachers during the course of their learning process.

\subsection{Present study}

This study intends to examine the preservice teachers through an experimental approach which will assist in critiquing the learners' academic performances without inducing uneasiness and when anxiety filters are induced. A systematic and theoretical analysis is required to readdress the issue of test anxiety thus a thorough cross examination gives a clear and empirical evidence to justify that test anxiety impacts on students 'academic performance or not. To address these, the following research questions were investigated: 
INTERNATIONAL JOURNAL OF EDUCATIONAL MANAGEMENT AND

DEVELOPMENT STUDIES

Volume 1, Issue 2 • December 2020 • ISSN 2719-0633 (PRINT) 2719-0641 (ONLINE)

1. What is the academic achievement of preservice teachers under a natural test setting?

2. What is the impact of test anxiety on the academic achievement of the preservice teachers?

The research questions provide a general view that the inducement of the test anxiety may adversely affect the academic performance of the learners. The current study posits that the test in a natural setting and a test under an induced stressed would have inverse results. As such, the following propositions were formulated:

1. The academic achievement of the preservice teachers is higher without test anxiety.

2. The academic achievement of the preservice teachers is lower with test anxiety.

\section{Methodology}

\subsection{Research Design}

The study adopts a mixed research design in eliciting useful information from the participants. This research design collects both qualitative and quantitative data through a test, questionnaire or interviews (Creswell \& Creswell, 2017) which deemed suitable for this study. The experimental research design determines the variability of the academic performance of the two groups of preservice teachers by manipulating one variable that could measure and calculate the impact of the test anxiety. Under this approach, the examination was conducted in the two groups of participants: the controlled group and an experimental group. The examination was conducted in its natural setting for the former while an artificially induced stress and anxiety were introduced before commencing the examination of the latter. For stress induction, the controlled group was allowed to sit for their examination under normal conditions whereas participants from the experimental group were told that their examination comprise an on-the-spot presentations before a panel of jury followed by the main examination to cause fear and uneasiness among the students. Meanwhile, during the oral presentations, the students were corrected severely to induce fear in them. These strategies have been suggested as an effective means of stress induction (Brouwer \& Hogervorst, 2014). Afterwards, the results obtained were compared and analyzed. 


\subsection{Participants}

The participants of this study were the 42 preservice teachers who were purposively chosen to ensure that same set participated throughout the study. These students were enrolled in a private university in North Cyprus. In order to carry out the experiment, the participants were divided into two treatment groups. The 3-credit unit language course was designed and utilized for the purpose of the research. The two classes were taught for two hours per lesson for a total of three months. The participants were coded as A1 to A21 for the first treatment group and B1 to B21 for the second treatment group. The examination was conducted for the two groups at the end of the three-month sessions. For the interviews, a zoom application was used to interview 10 participants coded as D1 to D10. Oral and written consent were received from the participants before the commencement of the research.

\subsection{Data Collection}

The major instrument for data collection was through the post-test and interviews. For the test, 17 itemized test was designed and administered to the two groups. The same questions were used for the two groups. A well-planned assessment strategy was developed to ensure the validity and reliability of the assessments as it was posited that high internal consistency and high quality of assessments require criterion-aided evaluation (Jonsson \& Svingby, 2007). The post-test was well-structured with a grading system prepared by three external examiners who adopted marking criteria to ensure inter-rater reliability of the instrument. McHugh (2012) notes that inter-rater reliability measures the extent to which data analyst assigns the same numerical score to the same variable. The examiners were experts from the faculty of education of the same private university who were conversant with administering and scoring tests. They were engaged in standardized sessions wherein the scores awarded to the students were reviewed until a consensus was agreed on a particular mark for a student performance. The criteria and breakdown of marks for the assessment ranging from 0 to 100 were discussed with the examiners who adopted holistic 
criteria for the assessment. A cut-off point of 50 to 100 points were set as 'passing grade' whereas 0 to 49 as 'fail grade' for the assessment.

After the marking, the scores were collated and presented in tables. Meanwhile, the use of zoom application for the interview session was due to lockdown regulations during the pandemic. Permission was received from the participants to record the interview sessions before the commencement. The interviews lasted for 1 hour, 15minutes and 45 seconds. At the end of the sessions, data were transcribed and analyzed.

\subsection{Data Analysis}

The results were calculated through the Statistical Package for Social Sciences (SPSS) version 23. The distribution table shows the test scores of the participants from the two groups. The interviews were descriptively analyzed using discourse analysis.

\section{Findings and Discussion}

\subsection{Test results}

RQ1: What is the academic achievement of preservice teachers under a natural test setting?

The controlled group consists of 21 students labeled A1 to A21. At the end of the three-month sessions in the 3-credit unit language course, these students were given a test under the normal conditions. Using a 17 items test, the students in this group completed the examination without induced fear and stress. There were no additional presentations and interviews thereafter. For the purpose of evaluation, the test scores 50 to 100 points are 'passing grade' whereas 0 to 49 are 'fail grade'.

The test scores of Group A students are presented. Table 1 shows the test scores of the students in the controlled group. 
INTERNATIONAL JOURNAL OF EDUCATIONAL MANAGEMENT AND

DEVELOPMENT STUDIES

Volume 1, Issue 2 • December 2020 • ISSN 2719-0633 (PRINT) 2719-0641 (ONLINE)

\section{Table 1}

Test scores of participants under controlled group

\begin{tabular}{ccc}
\hline Student Number & Test Score (\%) & Remarks \\
\hline A1 & 50 & $\mathrm{P}$ \\
A2 & 74 & $\mathrm{P}$ \\
A3 & 23 & $\mathrm{~F}$ \\
A4 & 34 & $\mathrm{~F}$ \\
A5 & 25 & $\mathrm{~F}$ \\
A6 & 28 & $\mathrm{~F}$ \\
A7 & 55 & $\mathrm{P}$ \\
A8 & 83 & $\mathrm{P}$ \\
A9 & 64 & $\mathrm{P}$ \\
A10 & 95 & $\mathrm{P}$ \\
A11 & 92 & $\mathrm{P}$ \\
A12 & 90 & $\mathrm{P}$ \\
A13 & 66 & $\mathrm{P}$ \\
A14 & 35 & $\mathrm{~F}$ \\
A15 & 42 & $\mathrm{~F}$ \\
A16 & 15 & $\mathrm{~F}$ \\
A17 & 15 & $\mathrm{~F}$ \\
A18 & 68 & $\mathrm{P}$ \\
A19 & 82 & $\mathrm{P}$ \\
A20 & 46 & $\mathrm{P}$ \\
A21 & 09 & $\mathrm{~F}$ \\
\hline
\end{tabular}

The table illustrates 12 out of 21 participants (57.1\%) obtained a passing grade for the assessment. This result coincides with the other researches which suggest that examination administered under a conducive learning environment may ensure that students achieve high academic performance (Poorman, Mastorovich \& Gerwick, 2019; Yusefzadeh, Iranagh \& Nabilou, 2019). Affirmatively, the results of the experiment found clear support for the assertions of similar studies that when the affective filter is reduced to the barest minimum, students' academic performance increases (Ironsi, 2017; Yusefzadeh, Iranagh \& Nabilou, 2019; Gerwing, Rash, Allen Gerwing, Bramble \& Landine, 2015).

A closer look at the table, 9 out of 21 students (42.8\%) obtained a fail grade in the assessment which relatively affirms several studies justifying that the issue of test anxiety is not a major determinant of students negative learning outcome (Brady, Hard \& Gross, 2018; Amy, 2017; Alicia, 2018). The results suggest that there is big discrepancy between the numbers of students with passing grades compared to the failed grades under the test with a 


\section{INTERNATIONAL JOURNAL OF EDUCATIONAL MANAGEMENT AND}

DEVELOPMENT STUDIES

Volume 1, Issue 2 • December 2020 • ISSN 2719-0633 (PRINT) 2719-0641 (ONLINE)

conducive environment. Thus, the results cast a new light on the possibility that test anxiety may not be the major cause of poor academic performances as the results indicate so.

RQ2: What is the impact of test anxiety on the academic achievement of the preservice teachers?

The experimental group consists of 21 students labeled B1 to B21. Using the same 3credit unit language course, these students were given a test at the end of three months with stress induction. Before the administration of the same 17-item test, the students gave an onthe-spot presentation before a panel of jury. The students were critiqued and corrected severely during the presentations. The same range of pass and fail scores is used for the interpretation of test scores.

Table 2

Test scores of participants under experimental group

\begin{tabular}{ccc}
\hline Student Number & Test Score \% & Remarks \\
\hline B1 & 32 & $\mathrm{~F}$ \\
B2 & 22 & $\mathrm{~F}$ \\
B3 & 25 & $\mathrm{~F}$ \\
B4 & 56 & $\mathrm{P}$ \\
B5 & 45 & $\mathrm{~F}$ \\
B6 & 46 & $\mathrm{~F}$ \\
B7 & 09 & $\mathrm{~F}$ \\
B8 & 15 & $\mathrm{~F}$ \\
B9 & 25 & $\mathrm{~F}$ \\
B10 & 32 & $\mathrm{~F}$ \\
B11 & 27 & $\mathrm{~F}$ \\
B12 & 22 & $\mathrm{~F}$ \\
B13 & 47 & $\mathrm{~F}$ \\
B14 & 57 & $\mathrm{P}$ \\
B15 & 95 & $\mathrm{P}$ \\
B16 & 85 & $\mathrm{P}$ \\
B17 & 48 & $\mathrm{~F}$ \\
B18 & 77 & $\mathrm{P}$ \\
B19 & 05 & $\mathrm{~F}$ \\
B20 & 28 & $\mathrm{~F}$ \\
B21 & 17 & $\mathrm{~F}$ \\
\hline
\end{tabular}


INTERNATIONAL JOURNAL OF EDUCATIONAL MANAGEMENT AND

DEVELOPMENT STUDIES

Volume 1, Issue 2 · December 2020 • ISSN 2719-0633 (PRINT) 2719-0641 (ONLINE)

Table 2 presents the test scores of participants in Group B, the experimental group. The table indicates that 5 out of 21 students (23.8\%) obtained a passing grade for the assessment while the $16(76.1 \%)$ obtained a fail grade. This result verifies that test anxiety through the induced fear and uneasiness among students invariably affects their academic achievements. This result affirms the position of most literature that test anxiety causes uneasiness among students during examination and a possible reason for their poor performances thereof (Gerwing, Rash, Allen Gerwing, Bramble \& Landine, 2015; Dan \& Raz, 2015; Krispenz, Gort, Schültke \& Dickhäuser, 2019). Moreover, the results attest to the other studies which deduce that test anxiety may be the sole reason behind poor grades of intelligent students who participate actively during classroom discussion yet perform badly during assessment periods (Safeer \& Shah, 2019; Ringeisen \& Heckel, 2019; Roy \& Post, 2018).

True as it may seem, the result also showed that the issue of test anxiety could vary from one student to another. As it is shown in the table that while a large number of students (16 or $23.8 \%$ ) failed the examination as a result of induced fear, a small number of students (5 or $76.1 \%$ ) were able to withstand the pressure of the induced fear and performed excellently during the examination. This novel finding further validates the conclusion of similar studies that test anxiety varies with individuals. While some may exhibit a high level of test anxieties, others may not (Ironsi, 2017; Amy, 2017).

Comparing the results of the two groups of students, there is critical evidence that test anxiety greatly affect the academic performance of the preservice teachers in a private university in North Cyprus. While the average test scores shows that students in the controlled group have higher academic performance, the participants in the experimental group have a failed average test score. Furthermore, the individual marks of the students show the inverse relationship between the two groups of participants. The number of students with passed mark in the experimental group (5) is even lower than the failed students' marks in the controlled group (9). This alone proves that the test anxiety greatly impact on the academic performance of the participants.

With the individual test scores provided as substantial evidence, the study affirms the propositions that the academic achievement of the preservice teachers is higher without test 
INTERNATIONAL JOURNAL OF EDUCATIONAL MANAGEMENT AND

DEVELOPMENT STUDIES

Volume 1, Issue 2 • December 2020 • ISSN 2719-0633 (PRINT) 2719-0641 (ONLINE)

anxiety which consequently give them lower academic achievement when there is test anxiety. Without reference to any other factors during the examination, it can be inferred that most of the students tend to underperform even with small amount of anxiety, pressure, stress, fear or uneasiness. Under the crucial situations during their examination, students cannot perform well even with proper preparations. As clearly implicated in the test results, the test anxiety has negative influence on the individual academic performance of the participants. Thus, a student performs better without text anxiety.

\subsection{Interview results}

An interview was conducted after the examination has been given to the two groups of students. The researcher selected 10 participants from the experimental group coded as D1 to D10. For the purpose of following the guidelines during the COVID19 pandemic, the researcher opted to use a virtual interview through Zoom application. The entire interview session was recorded for easy transcription of the answers. Oral and written consent were solicited prior to the interview.

There are series of semi-structured interview questions asked in order to elicit the opinion of the participants on their examination experience. This is to gather relevant facts to support the numerical data presented. Through a discourse analysis, the direct answers of the participants that satisfy the given question were lifted from the actual interview. The following are the generated answers from the interview.

\subsubsection{Do you feel anxious during the examination?}

When the participants were asked if they usually feel anxious during an examination, all the interviewees except D5, D3, and D10 indicated that they experience anxiety during an examination. Some of the interviewees explained some of the symptoms they experienced which make them feel not prepared for the examinations. Some of the statements include:

D1: "I usually have stomach pains during examinations and I don't know why this happens always" 
INTERNATIONAL JOURNAL OF EDUCATIONAL MANAGEMENT AND DEVELOPMENT STUDIES

Volume 1, Issue 2 • December 2020 • ISSN 2719-0633 (PRINT) 2719-0641 (ONLINE)

D7: “I feel anxiety when I'm preparing for an examination though I smoke a lot to reduce the stress and this helps me a lot"

D9: "I do not feel anxious about examinations especially when I'm prepared though some examinations may be frightening"

\subsubsection{Do you think your state of mind affects your performance during examinations?}

All the interviewees thought that their state of mind affects their performances during a particular test or examination. They further suggested that in most cases, the outcome of their performances does not fully represent their knowledge about a particular course or lesson. They also stated that examination results do not suggest students' knowledge of the course content as they believe that students have the tendency to cheat in numerous forms to obtain good grades. Here are some of their comments:

D2: "It does not bother me anymore because the environment of test affects my performance."

D5: "This does not mean that they know the course better than me, most of them can cheat to have good grades but I will never do that."

D10: “I don't like examinations because it affects my performance whereas I like projects and discussions as it allows me to share my opinions and viewpoints on a particular subject matter."

D3: “...some may cheat to obtain good grades, I try to do my best during examinations though the outcome of the examinations does not represent my knowledge of the lesson." 


\subsubsection{Do you think test anxiety affects your grades?}

All the participants except D3 and D10 thought that test anxiety affects the outcome of their academic performance. They alleged that an examination conducted when students are uneasy may affect the outcome of the grades. However, some of the interviewees stated that they do not believe in anxiety especially when they have prepared for examinations. They also affirmatively stated that examinations do not affect their grades or performances. Here are answers lifted from the interviewe:

D3: "It is impossible to experience anxiety when students are prepared for the examination. I'm always prepared for my exams and they do not affect my grades either."

D10: "Test anxiety is for very unserious students who are not interested in studying... Studying helps the student to prepare for an exam and when you do your part, there should not be fear of obtaining poor grades."

D2: "Of course test anxiety affects my performance...last semester I obtained bad grades as a result of anxiety."

D6: "I usually feel nervous during examinations and this affects my performance."

D7: "I hope things will change especially with the way examinations are conducted so it does not affect my grades, but I think my state of mind during exams affects my grades."

Based from the results of the interview, most of the students still assume the negative effect of anxiety on their academic performance. While some are aware of the need for exam preparations, still others are affected by the feeling of fear and anxiety during the examination. Generally, the interview data support the test results that there is potential impact of anxiety on the academic achievement of the students. 


\section{Conclusion}

This study investigated the impact of test anxiety on the academic performance of preservice teachers in a bid to reach practical and empirical consensus on the issue of test anxiety in education. The quantitative and qualitative findings confirm that test anxiety affects the academic performance of preservice teachers to a large extent. It is relatively clear from the results that the test anxiety has an impact on the academic achievements of students. However, the test anxiety is not the sole determinant of academic achievements of students. There are numerous other factors that play a vital role in determining the academic achievements of students. Although these other factors are not measured in this study, the results comparatively provide clear picture of test anxiety than the generalized nonexperimental studies. Through an experimental approach, the current study has proven its proposition that test anxiety negatively impact on the academic achievement of the students. Thus, students have higher academic achievement without test anxiety.

Although the results of the current study is relatively clear that test anxiety affects the academic performance of students, there are other contributory factors which are not measured in this study. As one of the primary limitations of the current study, it should be noted that test anxiety is not the sole determinant of learning outcomes. There are other relevant notable studies and reports confirming that anxiety can be managed to the advantage of the students. Arguably, taking other factors as constant, the paper concludes that high test anxiety directly influences the grades of the students. Relatively, the application of pressure either in the form of anxiety or stress may help motivate the students to learn. However, it is highly emphasized that due consideration be given as incidence of high induced pressure shows lower productivity and academic performance of students.

The results of the study suggests a need for a revisit and rethinking of the assessment methods in education. The emergence of recent study results pointing out that while some forms of assessments are essential for students' development, more emphasis should be given on designing assessments that are anxiety-free and friendlier so that test-takers can feel comfortable being assessed without them presuming assessments as judgement. The forms of assessment with over emphasis on grading should be reduced so that learners can conveniently participate. Given this, game-based assessments, final projects, collaborative 
INTERNATIONAL JOURNAL OF EDUCATIONAL MANAGEMENT AND

DEVELOPMENT STUDIES

Volume 1, Issue 2 • December 2020 • ISSN 2719-0633 (PRINT) 2719-0641 (ONLINE)

assessment, self-graded quizzes, collective portfolios and reflection-based assessments are highly suggested for effective measurement and evaluation that would not breed fear, trepidation or anxiety.

With the result of the study attesting to the impact of test anxiety on the student learning outcomes, it has a relevant and vital role in the educational pedagogy. This sends an implied message to all the teachers regardless of the levels and specializations. This imperatively calls for appropriate evaluation and assessment measures, proper strategies, relevant assessment design and immediate teacher intervention on the assessment implementation. Meanwhile, further research on the same nature are highly encouraged. The assessment of other relevant factors affecting the level of students' anxiety as well as the other factors affecting students' performance during examinations should also be considered for further analysis. As the current study has a small sample size, a larger sample size should also be considered for future researches.

\section{References}

Abdollahi, A., \& Abu Talib, M. (2015). Emotional intelligence moderates' perfectionism and test anxiety among Iranian students. School Psychology International, 36(5), 498512.

Alicia, H. C (2018) 7 Ways to Use Anxiety to Improve Performance. Retrieved from https://www.psychologytoday.com/intl/blog/hack-your-anxiety/201812/7-ways-useanxietyimproveperformance\#: : text $=$ Anxiety $\% 20 \mathrm{keeps} \% 20$ you $\% 20 \mathrm{alert} \% 2 \mathrm{C} \% 20 \mathrm{vigi}$ lant,threats\%2C\%20along\%20with\%20swift\%20action.

Amini, C. M. Amini, CM \& Reamen, JN (2019). Effects of Psychological Variables, Coping Strategies on Test Anxiety, and Academic Performance of Undergraduate Distance Learning Students in the National Open University of Nigeria. Journal of Education in Developing Areas (JEDA), vol. 7 (1)

Amy, M (2017, August 12) A new study says anxiety can help you perform better, but only if you know how to respond to it. Retrieved from

https://www.forbes.com/sites/amymorin/2017/08/12/a-new-study-says-anxiety-can-

help-you-perform-better-but-only-if-you-know-how-to-respond-to-

it/?sh=260f8de620f6

Brady, S. T., Hard, B. M., \& Gross, J. J. (2018). Reappraising test anxiety increases the academic performance of first-year college students. Journal of Educational Psychology, 110(3), 395.

Brouwer, A., \& Hogervorst, M. A. (2014). A new paradigm to induce mental stress: the Singa-Song Stress Test (SSST). Frontiers in Neuroscience, 8(224), 1-8. 
INTERNATIONAL JOURNAL OF EDUCATIONAL MANAGEMENT AND

DEVELOPMENT STUDIES

Volume 1, Issue 2 - December 2020 • ISSN 2719-0633 (PRINT) 2719-0641 (ONLINE)

Caspersen, J., Smeby, J. C., \& Olaf Aamodt, P. (2017). Measuring learning outcomes. European Journal of Education, 52(1), 20-30.

Carsley, D., \& Heath, N. L. (2018). Effectiveness of mindfulness-based coloring for test anxiety in adolescents. School Psychology International, 39(3), 251-272.

Carsley, D., Heath, N. L., \& Fajnerova, S. (2015). Effectiveness of a classroom mindfulness coloring activity for test anxiety in children. Journal of Applied School Psychology, 31(3), 239-255.

Corbett, M (2015). From law to folklore: work stress and the Yerkes-Dodson Law. Journal of Managerial Psychology. 30 (6):741-752. doi:10.1108/jmp-03-2013-

0085. ISSN $\underline{0268-3946}$

Creswell, J. W., \& Creswell, J. D. (2017). Research design: Qualitative, quantitative, and mixed methods approach. Sage publications.

Dan, O., \& Raz, S. (2015). The relationships among ADHD, self-esteem, and test anxiety in young adults. Journal of attention disorders, 19(3), 231-239.

Gerwing, T. G., Rash, J. A., Allen Gerwing, A. M., Bramble, B., \& Landine, J. (2015). Perceptions and Incidence of Test Anxiety. Canadian Journal for the Scholarship of Teaching and Learning, 6(3), 3.

Harris, R. B., Grunspan, D. Z., Pelch, M. A., Fernandes, G., Ramirez, G., \& Freeman, S. (2019). Can Test Anxiety Interventions Alleviate a Gender Gap in an Undergraduate STEM Course? CBE_Life Sciences Education, 18(3), ar35.

Ironsi, S.C (2017) Effect of test anxiety on academic performance of EFL Learners. Lambert Academic Publishing, ISBN:978-620-2-070620-3

Jonsson, A. \& Svingby, G. (2007). The use of scoring rubrics: Reliability, validity, and educational consequences. Educational Research Review, 2, 130-144. Available from https:// doi.org/10.1016/j.edurev. 2007.05.002

Krispenz, A., Gort, C., Schültke, L., \& Dickhäuser, O. (2019). How to reduce test anxiety and academic procrastination through inquiry of cognitive appraisals: Investigating the role of academic self-efficacy. Frontiers in psychology, 10, 1917.

McHugh, M. L. (2012). Interrater reliability: The Kappa statistic. Biochemia Medica, 22 (3), 276-282.

Owan, V. J., Eno, E. E., \& Esuong, U. (2019). Administration of punishment, students' test anxiety, and performance in Mathematics in secondary schools of Cross River State, Nigeria. International Journal of Academic Research in Business and Social Sciences, 9(6), 501-516.

Poorman, S. G., Mastorovich, M. L., \& Gerwick, M. (2019). Interventions for test anxiety: How faculty can help. Teaching and Learning in Nursing, 14(3), 186-191. 
INTERNATIONAL JOURNAL OF EDUCATIONAL MANAGEMENT AND

DEVELOPMENT STUDIES

Volume 1, Issue 2 • December 2020 • ISSN 2719-0633 (PRINT) 2719-0641 (ONLINE)

Ringeisen, T., \& Heckel, C. (2019). Relations Among Self-Efficacy, Test Anxiety, And Academic Performance: Theoretical and Empirical Considerations. Stress and Anxiety-Contributions of the STAR Award Winners, 171.

Riyazi, Z. (2019). The Effectiveness of Training Cognitive and Metacognitive Learning Strategies on Anxiety Test and Academic Performance of Nursing Students. Education Strategies in Medical Sciences, 11(6), 58-64.

Safeer, U., \& Shah, S. A. (2019). Effect of Test Anxiety On Academic Achievement Of University Students. Pakistan Journal of Physiology, 15(2), 76-79.

Sarı, S. A., Bilek, G., \& Çelik, E. (2018). Test anxiety and self-esteem in senior high school students: a cross-sectional study. Nordic Journal of Psychiatry, 72(2), 84-88.

Stoeber, J., Haskew, A. E., \& Scott, C. (2015). Perfectionism and exam performance: The mediating effect of task-approach goals. Personality and individual differences, 74, 171-176.

Townsley, M., \& Buckmiller, T. (2016). What does the research say about standards-based grading? Retrieved August 14, 2018.

Trigueros, R., Padilla, A. M., Aguilar-Parra, J. M., Rocamora, P., Morales-Gázquez, M. J., \& López-Liria, R. (2020). The Influence of Emotional Intelligence on Resilience, Test Anxiety, Academic Stress, and the Mediterranean Diet. International Journal of Environmental Research and Public Health, 17(6), 2071.

Vatterott, C. (2015). Rethinking grading: Meaningful assessment for standards-based learning. ASCD.

von der Embse, N., Jester, D., Roy, D., \& Post, J. (2018). Test anxiety effects, predictors, and correlates: A 30-year meta-analytic review. Journal of Affective Disorders, 227, 483493.

Wallis, A. L., Gretz, D. P., Rings, J. A., \& Eberle, K. M. (2019). Assessing marijuana use, anxiety, and academic performance among college students. Journal of College Counseling, 22(2), 125-137.

Weems, C. F., Scott, B. G., Graham, R. A., Banks, D. M., Russell, J. D., Taylor, L. K., \& Marino, R. C. (2015). Fitting anxious emotion-focused intervention into the ecology of schools: Results from a test anxiety program evaluation. Prevention Science, 16(2), 200-210.

Westerberg, T. R. (2016). Charting a course to standards-based grading: What to stop, what to start, and why it matters. $A S C D$.

Woldeab, D., \& Brothen, T. (2019). 21st Century assessment: Online proctoring, test anxiety, and student performance.

Yusefzadeh, H., Iranagh, J. A., \& Nabilou, B. (2019). The effect of study preparation on test anxiety and performance: a quasi-experimental study. Advances in Medical Education and Practice, 10, 245.

Zeidner, M. (2010). Test anxiety. The Corsini encyclopedia of psychology, 1-3. 